\title{
Responding to Patient-Initiated Verbal Sexual Harassment: Outcomes of a Pilot Training for Ophthalmologists
}

\author{
Lauren E. Hock, MD ${ }^{1}$ Brittni A. Scruggs, MD, PhD ${ }^{1,2}$ Patrick B. Barlow, PhD ${ }^{3}$ \\ Thomas A. Oetting, MD, MS ${ }^{1}$ Michael D. Abràmoff, MD, $\mathrm{PhD}^{1} \quad$ Erin M. Shriver, MD ${ }^{1}$

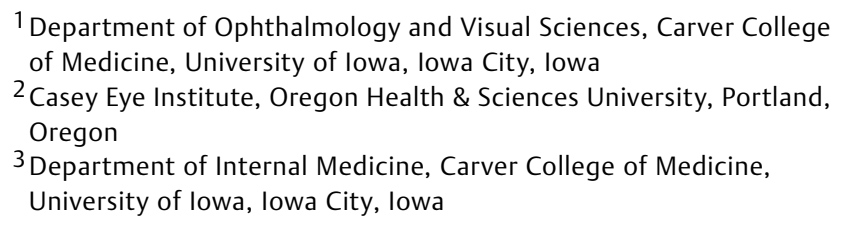 \\ Address for correspondence Thomas A. Oetting, MD, MS, University \\ of lowa Hospitals and Clinics, 200 Hawkins Drive, lowa City, IA 52242 \\ (e-mail: Thomas-Oetting@uiowa.edu). \\ J Acad Ophthalmol 2020;12:e175-e180.
}

\section{Abstract \\ Keywords \\ - ophthalmology \\ - resident \\ - sexual harassment \\ - toolkit \\ - workshop \\ - patient \\ - training \\ - gender}

Background Sexual harassment of physicians by patients is highly prevalent and rarely reported. Little is known on how to prepare physicians to handle verbal sexual harassment that detracts from their ability to provide care but does not meet the threshold for reporting.

Purpose To assess the impact of a sexual harassment workshop and toolkit for ophthalmologists and ophthalmology trainees on responding to patient-initiated verbal sexual harassment.

Methods A survey study of ophthalmology faculty, fellows, and residents who participated in workshops on responding to patient-initiated verbal sexual harassment was performed at an academic center. A toolkit of strategies for response was distributed. Volunteer participants completed a retrospective pretest-posttest evaluation at the conclusion of the workshop and follow-up survey 3 weeks after the workshops on whether they experienced harassment and intervened. The pretestposttest surveys assessed the workshop's effect on ophthalmologists' perceptions of and preparedness to respond to sexual harassment in the moment using a 5-point Likert scale, including bystander intervention. Participants described their responses observing and/or experiencing patient-initiated sexual harassment in the 3 weeks following the workshop and whether they had intervened toward the harassment.

Results Ophthalmologists $(n=31)$ felt significantly more prepared to respond to patient-initiated sexual harassment directed toward themselves or a trainee in the moment after participating in the workshop $(4.5 \pm 1.63)$ than before $(3.0 \pm 1.3)$ with a mean change of 1.6 (95\% confidence interval: $0.98-2.2, p<0.001)$. After the workshop, $86.3 \%$ of participants felt mostly or completely prepared to respond to comments about their age, gender, marital status, appearance, attractiveness, a specific body part, and sexual or inappropriate jokes. Most participants (83.9\%) said that they had not previously received training on techniques for responding to patientinitiated sexual harassment. Two-thirds (66.7\%) of participants who experienced received

March 3, 2020

accepted after revision

August 11, 2020
DOI https://doi.org/

10.1055/s-0040-1717062. ISSN 2475-4757.
Copyright $₫ 2020$ by Thieme Medical Publishers, Inc., 333 Seventh Avenue, New York, NY 10001, USA. Tel: +1(212) 760-0888.
License terms

(요 (1) $\Theta \circledast$ 
( $n=8)$ or observed $(n=13)$ harassment $(n=15)$ following the workshop intervened. All participants who intervened toward patient-initiated harassment behavior after the workshop $(n=10)$ found the Sexual Harassment Toolkit helpful in addressing harassment in the moment.

Conclusion Participation in a brief skills-based workshop significantly improved ophthalmologists' preparedness to respond to verbal sexual harassment by patients.

In response to national attention regarding sexual harassment in academic medicine, various authors have sought to characterize sexual harassment in the clinical setting. ${ }^{1-5}$ Cabrera et al demonstrated that $59 \%$ of mostly female ophthalmologists had experienced sexual harassment during their careers. Of those ophthalmologists, $87 \%$ reported significant impacts on their professional lives, including interference with their ability to work and a change in job or career. ${ }^{3}$ Surveys of resident physicians show that patients are the most frequent perpetrators of sexual harassment. ${ }^{4,6,7}$

The American Medical Association ${ }^{8}$ and National Academies of Sciences, Engineering, and Medicine ${ }^{9}$ have called for improved training on handling workplace sexual harassment, yet frameworks for responding to patient-initiated sexual harassment are lacking. ${ }^{10}$ The Accreditation Council for Graduate Medical Education (ACGME) has not published specific recommendations for dealing with harassment initiated by patients. ${ }^{11}$ Institutional training usually emphasizes harassment initiated by supervisors and may omit guidance on responding to harassment from patients, ${ }^{12,13}$ which is more likely to be reported among younger generations of physicians. ${ }^{14}$ Subtle harassment such as genderbased microaggressions is also more likely to go unnoticed by male physicians. ${ }^{15}$ Bystander intervention training toward sexual harassment has shown success in other fields ${ }^{16}$ and has been proposed as an antidote to sexual harassment in medicine. ${ }^{3,6}$ Bystander intervention training empowers individuals who are present but not directly involved in a harassment situation to diffuse the situation and help confront the harasser. ${ }^{17}$ However, existing literature on bystander training for physicians does not include data on the effects of training on physician preparedness to respond to harassment in the clinical setting. ${ }^{6,18}$ This study evaluates the impact of a pilot training workshop for ophthalmologists and ophthalmology trainees on techniques for responding to patient-initiated verbal sexual harassment on preparedness to respond to harassment behavior.

\section{Methods}

A survey study was conducted on the efficacy of a pilot workshop for ophthalmologists and ophthalmology trainees on responding to patient-initiated verbal sexual harassment. A female ophthalmology resident (L.E.H.) delivered the workshop as a supplement to mandatory institutional sexual harassment training. This required institutional harassment training could be completed in person as a passive lecture or as an online module and did not offer guidance on dealing with sexual harassment from patients and visitors. Department leadership invited all ophthalmology clinical faculty and ophthalmology trainees to participate in one of two 75minute workshops. The workshop was conducted in a large academic ophthalmology department of 37 faculty, 11 fellows, 15 ophthalmology residents, and 5 ophthalmology integrated interns. The workshop included discussion of the prevalence and impact of sexual harassment in medicine and application of the Sexual Harassment Toolkit ${ }^{19}$ strategies to clinical scenarios ( $\mathbf{- T a b l e ~} \mathbf{1}$ ).

At the end of the workshop, participants were invited to complete a confidential retrospective pretest-posttest survey $^{20}$ (Supplementary Material). The survey measured participants' self-rated abilities to complete the learning objectives before and after the workshop on a 5-point Likert scale from "very poor" (1) to "very good" (5). Participants also used a 5-point Likert scale to rate their preparedness to respond to forms of patient-initiated verbal sexual harassment. ${ }^{19}$ Three weeks after the workshop, a nonophthalmology department collaborator (P.B.B.) distributed an e-mail

Table 1 Sample role-play scenario and participant responses

\begin{tabular}{|l|l|}
\hline Scenario & Sample responses \\
\hline Resident: Please look at the screen and tell me & Resident: “''m sure you didn't mean anything by it, but I feel uncomfort- \\
what letters you can read from left to right. & $\begin{array}{l}\text { able when you comment on my appearance. I want to give you the best } \\
\text { care that I can so let's focus on your eyes/let's keep things professional." } \\
\text { Patient: You have a terrific body. }\end{array}$ \\
& $\begin{array}{l}\text { Bystander: "Sir, we ask that you treat all of our team members with } \\
\text { respect." }\end{array}$ \\
\hline
\end{tabular}

Notes: Participants took turns playing the roles of patient, resident, and bystander so that every role was experienced by each participant regardless of their gender or trainee/faculty status. Bystander intervention was defined as response to the verbal harassment by anyone present who was not the harasser or victim. Bystanders could be supervising faculty, senior residents, or other team members. 
Table 2 Harassment experiences of ophthalmologists and ophthalmology trainees by gender and primary role before participating in a workshop on tools for responding to patient-initiated verbal sexual harassment

\begin{tabular}{|c|c|c|c|c|c|c|c|c|}
\hline \multirow{2}{*}{$\begin{array}{l}\text { Harassment ex- } \\
\text { perience prior } \\
\text { to workshop }\end{array}$} & \multicolumn{4}{|l|}{ Gender } & \multicolumn{4}{|c|}{ Primary role } \\
\hline & $\begin{array}{l}\text { Male } \\
(n=19)\end{array}$ & $\begin{array}{l}\text { Female } \\
(n=12)\end{array}$ & OR $(95 \% \mathrm{Cl})$ & $p$-Value & $\begin{array}{l}\text { Trainee } \\
(n=16)\end{array}$ & $\begin{array}{l}\text { Faculty } \\
(n=15)\end{array}$ & OR $(95 \% \mathrm{Cl})$ & $p$-Value \\
\hline Experienced & 11 (57.9\%) & $12(100 \%)$ & $-^{a}$ & 0.012 & 13 (81.3\%) & $\begin{array}{l}10 \\
(66.7 \%)\end{array}$ & $\begin{array}{l}2.17(0.42- \\
11.30)\end{array}$ & 0.433 \\
\hline Observed & $13(68.4 \%)$ & 7 (58.3\%) & $\begin{array}{l}0.65 \\
(0.14-2.90)\end{array}$ & 0.567 & $10(62.5 \%)$ & $\begin{array}{l}10 \\
(66.7 \%)\end{array}$ & $\begin{array}{l}0.83 \\
(0.19-3.64)\end{array}$ & 0.809 \\
\hline $\begin{array}{l}\text { Observed and } \\
\text { intervened }\end{array}$ & 7 (36.8\%) & 5 (41.7\%) & $\begin{array}{l}1.22 \\
(0.28-5.37)\end{array}$ & 0.788 & $6(37.5 \%)$ & $\begin{array}{l}6 \\
(40 \%)\end{array}$ & $\begin{array}{l}0.90 \\
(0.21-3.82)\end{array}$ & 0.886 \\
\hline
\end{tabular}

Abbreviations: $\mathrm{Cl}$, confidence interval; OR, odds ratio.

Note: All comparisons were made using a combination of chi-square tests of independence or Fisher's exact tests, as appropriate.

${ }^{a} \mathrm{OR}$ could not be calculated because all female participants had experienced harassment.

link to a confidential follow-up survey assessing whether workshop participation affected participant intervention toward harassment by patients.

Statistical analyses with a two-tailed paired $t$-test were used for comparison of responses before and after the workshop, with significance defined as $p<0.05$. All statistical tests were performed using IBM SPSS v.25 (IBM, Inc.). The University of Iowa Institutional Review Board determined that this study did not constitute human subjects research and granted prospective approval and waiver of consent.

\section{Results}

Thirty-one ophthalmologists (15 faculty, 15 residents, 1 fellow; 19 male, 12 female) participated in the training workshops and $100 \%$ completed the survey (-Table 2 ). The majority of trainees $(81.3 \%)$ and faculty (66.7\%) responded that they had personally experienced verbal patient-initiated sexual harassment prior to the workshop. Significantly more women (100\%) than men (57.9\%) had personally experienced patient-initiated sexual harassment, regardless of professional role $(p=0.012)$. Among all participants, $83.9 \%$ said that they had not previously received training on techniques for responding to patient-initiated sexual harassment.

After the workshop, all participants reported significant increases in their perceived abilities to meet all learning objectives (-Table 3 ). Faculty and trainees felt more prepared to respond to patient-initiated sexual harassment toward themselves or a trainee after participating in the workshop (4.5 [good to very good] $\pm 1.63,95 \%$ confidence interval: $0.98-2.2)$ than before (3.0 \pm 1.3 [fair], $p<0.001)$. Most participants (86.3\%) felt mostly or completely prepared to respond to comments about their age, gender, marital status and comments about their appearance, attractiveness, a specific body part, and sexual or inappropriate jokes following the workshop. Nearly all ophthalmologists

Table 3 Paired comparisons of perceived abilities before and immediately after workshop

\begin{tabular}{|c|c|c|c|c|c|}
\hline \multirow[t]{2}{*}{ Item } & \multicolumn{3}{|l|}{ Mean (SD) } & \multicolumn{2}{|c|}{$\begin{array}{l}95 \% \mathrm{Cl} \text { of } \\
\text { difference }\end{array}$} \\
\hline & Before & After & Difference $^{a}$ & Lower & Upper \\
\hline $\begin{array}{l}\text { Recognize forms of patient-initiated sexual } \\
\text { harassment }\end{array}$ & $4.1(0.93)$ & $4.7(0.44)$ & $0.7(0.91)$ & 0.34 & 1.0 \\
\hline $\begin{array}{l}\text { Discuss the prevalence and impact of patient- } \\
\text { initiated sexual harassment on trainees and the } \\
\text { learning environment }\end{array}$ & $3.4(1.11)$ & $4.7(0.54)$ & $1.3(1.14)$ & 0.91 & 1.7 \\
\hline $\begin{array}{l}\text { Describe the role of supervisors and colleagues } \\
\text { in monitoring and responding to patient-initi- } \\
\text { ated sexual harassment and identify potential } \\
\text { barriers to this }\end{array}$ & $3.4(1.08)$ & $4.6(0.67)$ & $1.2(1.26)$ & 0.76 & 1.7 \\
\hline $\begin{array}{l}\text { Respond directly to patient-initiated sexual } \\
\text { harassment toward you or a trainee in the } \\
\text { moment }\end{array}$ & $3(1.3)$ & $4.5(0.89)$ & $1.6(1.63)$ & 0.98 & 2.2 \\
\hline
\end{tabular}

Abbreviations: $\mathrm{Cl}$, confidence interval; SD, standard deviation.

Notes: Perceived abilities to perform the learning objectives before and after the workshop were rated on a 5-point Likert scale. A score of "1" signified very poor ability. A score of " 5 " signified very good ability.

${ }^{a}$ All differences are statistically significant at $p<0.001$. 
Table 4 Harassment experiences of ophthalmologists and ophthalmology trainees in 3 weeks following a workshop on tools for responding to patient-initiated verbal sexual harassment

\begin{tabular}{|l|l|l|l|l|l|l|l|l|}
\hline $\begin{array}{l}\text { Harassment } \\
\text { experience } \\
\text { after the } \\
\text { workshop }\end{array}$ & \multicolumn{3}{|l|}{ Frequency (\%) of experiences $(n=21)$} & \multicolumn{2}{|l|}{$\begin{array}{l}\text { Frequency of intervention when } \\
\text { experienced }(\boldsymbol{n}=10)^{\mathrm{a}}\end{array}$} \\
\cline { 2 - 8 } & Only once & $\begin{array}{l}\text { Two to } \\
\text { five times }\end{array}$ & $\begin{array}{l}\text { Six to } \\
\text { nine times }\end{array}$ & $\begin{array}{l}\text { Daily or } \\
\text { almost } \\
\text { daily }\end{array}$ & $\begin{array}{l}\text { More than } \\
\text { once per } \\
\text { day }\end{array}$ & $\begin{array}{l}\text { Intervened } \\
\text { on own } \\
\text { behalf }\end{array}$ & $\begin{array}{l}\text { Intervened } \\
\text { on behalf } \\
\text { of a trainee }\end{array}$ & $\begin{array}{l}\text { Intervened } \\
\text { on behalf } \\
\text { of a peer }\end{array}$ \\
\hline $\begin{array}{l}\text { Experienced } \\
(n=8)\end{array}$ & $1(12.5 \%)$ & $3(37.5 \%)$ & $1(12.5 \%)$ & $2(25.0 \%)$ & $1(12.5 \%)$ & $6(60.0 \%)$ & $4(40.0 \%)$ & $4(40.0 \%)$ \\
\cline { 1 - 5 } & $\begin{array}{l}\text { Observed } \\
(n=13)\end{array}$ & $2(15.4 \%)$ & $5(38.5 \%)$ & $3(23.1 \%)$ & $3(23.1 \%)$ & $0(0.0 \%)$ & & \\
\hline
\end{tabular}

Note: All comparisons were made using a combination of chi-square tests of independence or Fisher's exact tests, as appropriate.

${ }^{a}$ Nine out of 10 responses to this question could be matched to their gender on the original survey. Of those 9,5 ( $55.6 \%$ ) identified as male and 4 $(44.4 \%)$ identified as female.

(93.5\%) stated that the training helped them feel more prepared to respond to other types of harassment (e.g., harassment based on age, race, religion, or sexual orientation).

Twenty-three participants $(23 / 31,74.1 \%)$ completed the online follow-up survey 3 weeks after the workshop with 21 participants (13 men, 8 women; 11 faculty, 10 residents/fellows) completing the survey completely. Patient-initiated harassment was experienced $(n=8,34.7 \%)$ and/or observed $(n=13,56.5 \%)$ by 15 participants $(15 / 21$, $65.2 \%$ ) in the 3 -week period (-Table 4 ). Only $25 \%$ of women $(2 / 8)$ and $46.2 \%$ of men $(6 / 13)$ did not observe or experience patient-initiated sexual harassment. Five participants (23.8\%) observed patient comments about a specific body party, sexual jokes, or gestures (i.e., a score of 3 out of 5 on the verbal sexual harassment scale ${ }^{7}$ ) (Supplementary Material). Three physicians (14.3\%) experienced verbal harassment initiated by patients "almost daily" to "more than once per day."

Ten (66.7\%; 5 male, 4 female, 1 did not identify gender) of the 15 participants who experienced or observed harassment following the workshop reported that they had addressed the harassment behavior. Most participants (60\%) intervened on their own behalf. Two participants (13.3\%) said that they encouraged reporting of severe or pervasive sexual harassment. All participants (10/10) who intervened found the toolkit helpful in dealing with the harassment.

\section{Discussion}

This study provides the first pretest-posttest and follow-up evaluation of a pilot training program on techniques for responding to patient-initiated sexual harassment of ophthalmologists and ophthalmology trainees. ${ }^{19}$ Participation in the workshop significantly improved trainee and faculty preparedness to intervene toward verbal patient-initiated harassment. All participants (100\%) reported that participating in the workshop had changed their perceptions of the frequency and severity of sexual harassment by patients.
Workshop participation may have affected ophthalmologists' and ophthalmology trainees' decision to intervene toward verbal sexual harassment by patients. Two-thirds (66.7\%) of the workshop participants who experienced or observed harassment in the 3-week follow-up period reported that they had intervened compared with $38.7 \%$ of participants who had ever intervened before the workshop. All participants (100\%) who intervened reported finding the Sexual Harassment Toolkit helpful in dealing with the situation.

Notably, all female workshop participants and most male participants reported that they had experienced patientinitiated sexual harassment before the workshop. Given nearly $85 \%$ of participants reported no previous training on responding to patient-initiated verbal sexual harassment, there is a great unmet need for this type of targeted training program. Furthermore, the workshop strategies may be applied to other forms of identity-based harassment initiated by patients, such as discrimination based on race, age, or religion. $^{21}$

This study has several limitations. First, it evaluates a single institution, first-of-its-kind training program designed for responding to less severe forms of verbal harassment. The sample size was small, with 31 participants and 21 completing the entire follow-up survey (67.7\%). The workshop was also voluntary and may not capture the experiences of all potential participants. Several faculty and fellows were unable to attend either workshop session due to conflicts with surgical duties. However, there was a high level of ophthalmology resident engagement with 15 of the 17 available residents participating.

This pilot study suggests that response rehearsal using a Sexual Harassment Toolkit may affect physicians' decisions to respond to sexual harassment initiated by patients. However, training workshops alone are unlikely to overcome department and institutional norms regarding addressing inappropriate patient behavior. Ophthalmology trainees working in an attending clinic may not feel comfortable calling out harassment if their supervising faculty do not view it as a problem. ${ }^{22}$ Fear of negative patient reviews may also affect ophthalmologists' willingness to confront 
discriminatory behavior. Explicit statements of support from department leadership and modeling of bystander intervention when it occurs could help address these concerns.

Finally, it should be noted that the workshop content was tailored to the ophthalmology department surveyed to maximize its clinical relevance. The workshop activities were led by an ophthalmology trainee and all role-play scenarios were based on actual patient comments toward female ophthalmology residents. During role-play activities, the pairing of ophthalmology trainees with faculty members seemed to encourage reflective discussion. Support from department leadership and use of dedicated education rounds time were key in promoting trainee and faculty participation. A future multicenter study could help elucidate which activities and participant groups (e.g., genderinclusive vs. all-female or all-male groups) are most effective at improving participant preparedness to address harassment.

\section{Conclusion}

Most ophthalmologists should expect to encounter patientinitiated sexual harassment toward themselves or toward their trainees and/or peers. While this pilot program focused on skills for responding to verbal sexual harassment, these skills can also be used to address other forms of harassment. To enact change, all physicians should be prepared to call out harassment. While the principle of primum non nocere (first, do no harm), typically is interpreted to apply to our care for patients, it also applies to the care for our colleagues and ourselves as physicians.

\section{Funding}

The authors acknowledge the support of an unrestricted grant to the University of Iowa, Department of Ophthalmology and Visual Sciences from Research to Prevent Blindness, Inc., New York, NY. Dr. Abramoff received support from the National Institutes of Health Center Core (grant number: P30EY025580). There are no relevant financial disclosures for any author.

\section{Conflicts of Interest}

Dr. Abramoff reports grants and personal fees from Department of Veteran Affairs, grants and personal fees from University of Iowa Hospitals and Clinic, personal fees from IDx Technologies Inc, grants from National Institute of Health, during the conduct of the study; grants from National Institute of Health, personal fees from University of Iowa Health Clinics, personal fees from IDX Technologies Inc, grants from Department of Veterans Affairs, outside the submitted work. In addition, Dr. Abramoff has a patent Automatic Detection of Red Lesions in Digital Color Fundus Photographs licensed to IDX, a patent Automated Classification of Stereo Color Images of the Optic Nerve Head licensed to IDX, a patent Method for Optimal Detection of Surfaces in n-Dimensional Data licensed to IDX, a patent Optimal Registration of Multiple Deformed Images using a Physical Model of the Imaging Distortion licensed to IDX, a patent Technique for Discovering the Optimal Features for Classifying Patterns or Objects in Images licensed to IDX, a patent Hybrid Laser Ophthalmoscope licensed to IDX, a patent Optimal, User-Friendly, Object Background Separation in Images licensed to IDX, a patent Retinal Image Feature Detection Method Using Deep Neural Networks Đpending to IDX, a patent Systems and methods for alignment of the eye for ocular imaging licensed to IDX, a patent System and Methods for Qualifying medical images pending, a patent Automated Separation of Binary Overlapping Trees licensed to IDX, a patent Snapshot spectral domain optical coherence tomographer licensed to IDX, a patent Automated Assessment of Glaucoma Loss from Optical Coherence Tomography licensed to IDX, a patent Parallel Optical Coherence Tomography Apparatuses licensed to IDX, a patent Automated Determination Of Arteriovenous Ratio In Images Of Blood Vessels licensed to IDX, a patent Automated Assessment of Glaucoma Loss from Optical Coherence Tomography pending, a patent System and method for optical imaging of human retinal function pending, a patent Methods and Systems for Vessel Bifurcation Detection pending, a patent Graph Search Using Non-Euclidean Deformed Graph pending, and a patent System and methods for n-dimensional image segmentation using convolutional neural networks pending.

\section{References}

1 Jenner S, Djermester P, Prügl J, Kurmeyer C, Oertelt-Prigione S. Prevalence of sexual harassment in academic medicine. JAMA Intern Med 2019;179(01):108-111

2 Fnais N, Soobiah C, Chen MH, et al. Harassment and discrimination in medical training: a systematic review and meta-analysis. Acad Med 2014;89(05):817-827

3 Cabrera MT, Enyedi LB, Ding L, MacDonald SM. Sexual harassment in ophthalmology: a survey study. Ophthalmology 2019;126(01): 172-174

$4 \mathrm{Hu}$ YY, Ellis RJ, Hewitt DB, et al. Discrimination, abuse, harassment, and burnout in surgical residency training. N Engl J Med 2019;381(18):1741-1752

5 Espinoza M, Hsiehchen D. Characteristics of faculty accused of academic sexual misconduct in the biomedical and health sciences. JAMA 2020;323(15):1503-1505

6 McKinley SK, Wang LJ, Gartland RM, et al; Massachusetts General Hospital Gender Equity Task Force. "Yes, I'm the doctor": One department's approach to assessing and addressing gender-based discrimination in the modern medical training era. Acad Med 2019;94(11):1691-1698

7 Scruggs BA, Hock LE, Cabrera MT, Wang K, Oetting TA, Abràmoff MD, Shriver EM. A U.S. Survey of Sexual Harassment in Ophthalmology Training Using a Novel Standardized Scale. Journal of Academic Ophthalmology 2020;12(01):e27-e35

8 O'Reilly KB. AMA principles will further gender equity among physicians. American Medical Association. Physician Diversity Web site. Available at: https://www.ama-assn.org/practicemanagement/physician-diversity/ama-principles-will-furthergender-equity-among-physicians. Published 2019. Accessed July 18, 2019

9 National Academies of Sciences Engineering Medicine. Together We Can Do Better: A Gathering of Leaders in Academia to Prevent Sexual Harassment: Proceedings of a Workshop-in Brief. Washington, DC: The National Academies Press; 2019 
10 Viglianti EM, Oliverio AL, Meeks LM. Sexual harassment and abuse: when the patient is the perpetrator. Lancet 2018;392 (10145):368-370

11 ACGME. Non-Discrimination Policy. Available at: https://www. acgme.org/About-Us/Legal/Non-Discrimination-Policy. Published 2020. Accessed June 23, 2020

12 Alfandre D, Geppert C. Discriminatory and sexually inappropriate remarks from patients and their challenge to professionalism. Am J Med 2019;132(11):1251-1253

13 Warsame RM, Hayes SN. Mayo Clinic's 5-step policy for responding to bias incidents. AMA J Ethics 2019;21(06):E521-E529

14 Shrier DK, Zucker AN, Mercurio AE, Landry LJ, Rich M, Shrier LA. Generation to generation: discrimination and harassment experiences of physician mothers and their physician daughters. J Womens Health (Larchmt) 2007;16(06):883-894

15 Periyakoil VS, Chaudron L, Hill EV, Pellegrini V, Neri E, Kraemer HC. Common types of gender-based microaggressions in medicine. Acad Med 2020;95(03):450-457

16 Katz J. Bystander training as leadership training: notes on the origins, philosophy, and pedagogy of the Mentors in Violence Prevention model. Violence Against Women 2018;24(15): 1755-1776
17 Aggarwal R, Brenner AM. \#MeToo: the role and power of bystanders (aka us). Acad Psychiatry 2020;44(01):5-10

18 Goldenberg MN, Cyrus KD, Wilkins KM. ERASE: a new framework for faculty to manage patient mistreatment of trainees. Acad Psychiatry 2019;43(04):396-399

19 Hock LE, Scruggs BA, Oetting TA, Abramoff MD, Shriver EM. Tools for responding to patient-initiated verbal sexual harassment. Available at: https://EyeRounds.org/tutorials/sexual-harassment-toolkit/index.htm. Updated August 20, 2019. Accessed August 2, 2020

20 Pratt CC, McGuigan WM, Katzev AR. Measuring program outcomes: using retrospective pretest methodology. Am J Eval 2000; 21(03):341-349

21 Goodman DJ. Responding to biased or offensive comments. Adapted from Promoting Diversity and Social Justice: Educating People from Privileged Groups New York: Routledge; 2011. Available at: https://dianegoodman.com/wp-content/uploads/ 2020/05/RespondingToBiasedOrOffensiveCommentsexcerptarticle.pdf. Accessed August 2, 2020

22 Wheeler DJ, Zapata J, Davis D, Chou C. Twelve tips for responding to microaggressions and overt discrimination: when the patient offends the learner. Med Teach 2018:1-6 